\title{
Representación y violencia en el fútbol peruano: Barras bravas
}

\author{
Aldo PANFICHI
}

El fútbol en los últimos años ha dejado de ser sólo una pasión deportiva para convertirse en un escenario privilegiado para el estudio de la sociedad. Sociólogos, antropólogos y comunicadores en distintas partes del mundo han descubierto que el fútbol no es sólo un grupo de hombres corriendo detrás de una pelota, sino que en él se representan relaciones humanas, comportamientos colectivos y aspiraciones que surgen de experiencias que han impactado fuertemente en la vida diaria de grupos humanos que constituyen una sociedad determinada. Creemos que existe una estrecha relación entre el tipo de experiencia histórica vivida y aquellos aspectos sociales y culturales que el fútbol ilumina en cada país.

En Perú, al igual que en Inglaterra y Argentina, el interés académico por el fútbol se centra sobre todo en el comportamiento y la cultura de violencia que muestran los jóvenes integrantes, mayoritariamente hombres, de las llamadas barras bravas. En otros países con experiencias políticas autoritarias, como España y Chile, se estudia el uso político del fútbol como instrumento de control social (el respaldo de dictadores como Franco y Pinochet a clubes como Real Madrid y Colo Colo) o de resistencia popular al autoritarismo (Atlético de Madrid y la Universidad de Chile).

La capacidad que tiene el fútbol de representar aspectos centrales de la vida de los pueblos radica en el hecho de que el fútbol en sí es una representación ritual, vacía de significados históricos específicos, de un enfrentamiento no violento entre dos comunidades fuertemente cohesionadas e identificadas. Esta "naturaleza" universal del fútbol, como 
1. Dunning, Murphy y Routledge Williams The Roots of Football Hooligalism. An Historical and Sociological Study. London: Euricetel, 1988.

2. Panfichi, Aldo. "Fútbol e identidad: esta urgencia de decir nosotros". Fútbol, identidad, violencia $y$ racionalidad, varios autores. Temas en Sociología $\mathrm{N}^{\circ} 1$. Lima: Pontificia Universidad Católica del Perú, 1995. señala Eric Dunning, la convierte en una metáfora donde se "entrelazan sutilmente formas de cooperación, interdependencia y conflicto" que llevan a la formación de grupos o comunidades antagónicas. Además, este enfrentamiento despierta emociones, tanto placenteras como dolorosas, que compensan necesidades personales y de búsqueda de status y reconocimiento social ${ }^{1}$.

De esta manera, en el fútbol se enfrentan once individuos contra once, distribuidos en el campo en posiciones de ataque y defensa, identificados ambos grupos con colores y emblemas distintos que explicitan un sentido de pertenencia de "nosotros versus ellos", siendo la victoria para aquéllos que penetran en el corazón del equipo rival, humillan al rival, y logran marcar el gol. Luego habrá que defender la ventaja y salir del campo victoriosos. Esta representación simbólica, además, ocurre en un espacio público construido exclusivamente para este fin como es un estadio y con un árbitro y reglas que todos civilizadamente deben de respetar.

A esto habría que agregar que el fútbol es también un fenómeno masivo y pluriclasista que crea formas de identidad irreductibles. Para ello crea lazos emocionales de lealtad e identificación grupal entre personas de distintos estratos, razas, clases, ocupaciones o preferencias sexuales. Estas lealtades cruzan toda forma de organización e institucionalidad, convirtiéndose en uno de los mecanismos de diferenciación social de mayor relevancia en las sociedades contemporáneas. Las lealtades se organizan alrededor de valores y significados que se encarnan en el aura y la simbólica que identifica a un club de fútbol determinado ${ }^{2}$. En sí mismo el fútbol es una representación ritual del enfrentamiento entre dos comunidades diferenciadas. No es el causante directo del comportamiento violento de ciertos grupos de aficionados. Por el contrario, son estos individuos y la manera como procesan las experiencias históricas que les ha tocado vivir las que dan origen a los contenidos específicos que se ponen en juego en esta representación.

En el Perú, como indicamos previamente, el aspecto del fútbol que concita mayor atención es la violencia que provocan grupos de jóvenes hombres organizados alrededor de distintas barras bravas. La pregunta es, entonces, qué tipo de experiencias y contenidos nacionales están detrás de este comportamiento juvenil. En otras palabras, qué experiencias se representan en el fútbol. Evidentemente, para responder adecuadamente esta pregunta debemos prestar atención tanto a procesos históricos de larga duración como a factores que provienen de períodos o coyunturas históricas más recientes. Sin embar- 
go, en este artículo pondremos énfasis sobre todo en el segundo tipo de factores, los cuales nos parecen centrales en la explicación del problema, dejando para otra oportunidad el intento de una interpretación basada en la larga duración.

Partimos de la idea de que no es casual que la violencia en el fútbol peruano se convierta en un "problema" de mayor visibilidad inmediatamente después de un período de enfrentamiento, muerte y destrucción, que culminó con la victoria política y militar del estado peruano sobre grupos subversivos alzados en armas. No debemos olvidar que diversas organizaciones internacionales de derechos humanos estiman que cerca de 30 mil peruanos, en su mayoría jóvenes, murieron por causa de este enfrentamiento entre 1980 y 1992 . Y que los daños materiales ocasionados se estiman en un valor aproximado de 27.000 millones de dólares.

La experiencia de este enfrentamiento militar alcanzó a todos los sectores sociales, algunos más que a otros, como veremos luego, pero nadie en el Perú puede afirmar que pasó incólume estos duros años. Más aún, toda una generación de jóvenes nació y se socializó en medio de este enfrentamiento que, además, pudo ser seguido diariamente y en vivo y en directo a través de los medios de comunicación masivos.

La primacía que damos al factor de la guerra interna no quiere decir que pensemos que no ha existido violencia en el fútbol peruano antes de este período. En realidad, éste es un tema aún no estudiado y constituye un vacio importante en el conocimiento de nuestra historia social cultural. Sin embargo existen algunos hechos que llaman a reflexión. Por ejemplo, que el primer clásico del fútbol peruano, es decir aquel partido fundacional entre Alianza Lima y Universitario que da origen o "inventa" la más importante rivalidad de nuestro fútbol, ocurrió en setiembre de 1928 y terminó antes del tiempo reglamentario por una gresca generalizada en la que participaron no sólo los jugadores sino también los aficionados que dejaron las graderías para invadir el campo de juego. Este evento es también conocido como el clásico de los bastones, ya que éstos se utilizaron como armas en las peleas. Años más tarde, el 24 de mayo de 1964, un partido entre los seleccionados nacionales de Perú y Argentina terminó en la mayor tragedia ocurrida en un campo de fútbol en el mundo, cuando multitudes descontroladas por lo que ellas consideraban un fallo injusto invadieron el terreno de juego siendo duramente reprimidos por la policía. El resultado de la estampida provocada por la multitud al huir de la represión y encontrar las puertas del estadio cerradas fue de 328 aficionados muertos y cerca de 500 heridos. 
No obstante los hechos indicados, y admitiendo la falta de una mayor investigación histórica, creemos que hay indicios suficientes para afirmar que es a partir de los años ochenta, y sobre todo en los noventa, que el fútbol -de manera paulatina pero sostenida- se convierte para un grupo importante de jóvenes en un espacio de representación de la violencia. En efecto, es en este período que ocurre un cambio significativo en la composición y organización social de las barras de fútbol, en sus formas de comportamiento colectivo, en sus cánticos y expresiones verbales, y en su transformación en un espacio central para la construcción de formas de masculinidad radical y agresiva. Todo lo cual ha convertido a estas barras en un nuevo actor social, temido e incluso vilipendiado, pero poco conocido.

\section{LAS BARRAS BRAVAS}

Diversos analistas coinciden en afirmar que en los primeros años de la década del ochenta, los seguidores de los equipos más populares del Perú se ubicaban en los estadios de acuerdo a criterios de identificación de clase. De un lado, los barristas de Alianza Lima, el equipo popular por excelencia, se ubicaban en la tribuna popular sur y, de otro lado, los seguidores de Universitario se ubicaban en la tribuna oriente propia de las clases medias. Ambas barras eran grupos de hinchas "decentes" y poco organizados que se reunian en el estadio para apoyar a sus respectivos equipos y que, además, contaban con el reconocimiento oficial del club. Este reconocimiento implicaba entradas de cortesía y una vinculación privilegiada con el club, la cual era fuente de poder y la base sobre la cual, muchas veces, se construian relaciones de clientelismo y paternalismo. Se señala, incluso, que varios de los organizadores "históricos" de estas barras luego se convertirian en empleados de los clubes o de las empresas de sus ocasionales dirigentes. En esos años, los mismos en que se inicia la guerra subversiva en el Perú, los clubes de fútbol tuvieron un fuerte control sobre la organización y comportamiento de sus seguidores.

Sin embargo, a fines de los años ochenta e inicios de los noventa esta situación se va modificando. Son años de agravamiento de la crisis económica, deterioro del orden público, desempleo general, y sobre todo de violencia y terrorismo indiscriminado. En este contexto las barras van escapando del control de sus dirigentes "históricos", al mismo tiempo que se convierten en un fuerte polo de atracción para miles de jóve- 
nes y adolescentes de los barrios marginales. El estilo confrontacional e infractor de las normas de conducta socialmente aceptadas se va delineando como una característica central de estos jóvenes. Al mismo tiempo, las barras se van dotando de formas más complejas de organización al centralizar bajo su mandato a numerosos grupos de jóvenes cohesionados territorialmente en barras distritales o locales. Todas ellas hermanadas por sentimientos de lealtad e identidad a un club de fútbol determinado.

En el caso de Universitario de Deportes, este proceso ha sido bien descrito por Raúl Castro, quien señala que la barra conocida con el nombre de "Trinchera Norte" se funda en 1988 como una disidencia de la barra oficial del club ubicada en la tribuna de oriente. "Trinchera" reclama una nueva identidad mudándose a la tribuna popular norte, pero sobre todo afirma la necesidad de defender su emblema de los ataques de su barra archienemiga, "Comando Sur" de Alianza Lima, y de organizar a su "ejército" para pasar al "contraataque". Tareas éstas que no habrian sido asumidas por la barra oficial de oriente, lo cual habría dado origen al estigma de "gallinas"3. Poco a poco la "Trinchera Norte" va ganando su legitimidad y autoridad en las calles al tiempo que desaparece la barra crema de oriente.

En términos organizativos, las barras pasan de ser una sola organización centralizada en un núcleo de dirigentes antiguos a una red de grupos barriales que se extienden por toda la ciudad. De esta manera las disputas y enfrentamientos que se representan en el fútbol pasan del campo de juego y las tribunas del estadio a la vida local de los barrios. La ciudad entera se convierte en un terreno de disputa real y simbólico. Las barras distritales se enfrascan en luchas territoriales por el uso social del espacio local, y en esto adquiere importancia el graffiti como una marca de apropiación territorial. Así, las lealtades futbolísticas crean y reproducen nuevas líneas de diferenciación social entre las personas, las cuales se vienen a sumar a otros criterios como clase, origen, edad, género u ocupación. Asimismo, la pertenencia a un grupo barrial se convierte en una identidad local diferenciada al interior de una identidad futbolística mayor.

Este proceso, para el caso de Universitario, se acelera desde 1994 cuando la "Trinchera" organiza un sistema descentralizado de reparto de entradas de cortesía a los emergentes grupos barriales. Como indica Atilio Espinosa, hasta ese momento el reparto lo realizaban centralizadamente los jefes de la barra en los alrededores de los estadios donde jugara Universitario. Con el nuevo sistema los grupos barriales
3. Castro, Raúl (1995) "U-Norte: de la marginalidad a la representación colectiva", en ibídem. 
4. Espinosa, Atilio (1998): "Mi barrio es zona crema. Territorialidad y conflicto en un grupo barrial de Trinchera Norte". Paper presentado al seminario Juventud, Sociedad y Cultura, Red para el Desarrollo de las Ciencias Sociales en el Perú.

5. Benavides, Martín (1997): "Fútbol y tradiciones inventadas: el caso de Alianza Lima". Tesis para obtener el título de licenciado en sociología. Pontificia Universidad Católica del Perú. tienen mayor importancia como canales de distribución de beneficios al tiempo que surgen nuevos líderes que pronto reclamaron su lugar en la directiva central de la barra 4 . Estos nuevos líderes, además, buscan renegociar sus vinculaciones con los dirigentes del club marcando una mayor autonomía que sus predecesores.

Un proceso parecido muestra Martín Benavides para el caso del "Comando Sur" de Alianza Lima. En esta barra, popular de sus inicios, las jerarquias internas estaban revestidas de un fuerte sentido familístico y comunitario. Los dirigentes antiguos imponían su autoridad en nombre de la fidelidad a la tradición que sostiene a esta comunidad como una gran familia o hermandad espiritual. De alli el poder cohesivo que tiene la noción de intimidad en esta comunidad. Sin embargo, en la medida que "Comando Sur" fue integrando a otros grupos barriales ocurrió lo mismo que con "Trinchera Norte". Es decir, el poder y la legitimidad de los dirigentes antiguos se vio cuestionada ${ }^{5}$.

La respuesta al desafio fue muchas veces violenta y ello explica por qué un grupo de jóvenes en 1993 formó la barra disidente "Los Cabezas Azules", quienes fueron obligados a salir de tribuna sur y ubicarse en tribuna norte, hasta ese momento territorio exclusivo de la barra de Universitario. Los "Cabezas Azules", no obstante sus repetidos esfuerzos, no pudieron atraer a otros grupos barriales por el poder simbólico que tiene la tribuna sur para todo hincha blanquiazul y, además, por no tener acceso a las entradas de cortesía que monopoliza "Comando Sur". En 1997 el proceso se repite aunque con otro resultado. Esta vez una alianza de grupos barriales encabezados por los "Sicarios", "Barraca Rebelde" y "Agustigrone", todos ellos liderados por jóvenes entre 16 y 22 años, destronaron finalmente el poder de los antiguos y capturaron la dirigencia central de "Comando Sur".

\section{CULTURA DE LA VIOLENCIA}

Uno de los legados más importantes de los años de violencia política es el enraizamiento entre los peruanos de una especie de sentido común de guerra o enfrentamiento. Un sentido común que gobierna muchas de las relaciones humanas y que se expresa en la violencia del lenguaje, en la legitimidad que adquiere la imposición y en la prepotencia del "gana gana" en semáforos o colas en oficinas publicas o privadas. En general, creemos que hay traspaso de nombres, formas, símbolos, enseñanzas y emblemas propios de la vio- 
lencia politica hacia otras prácticas sociales, entre las cuales se encuentra el comportamiento y la iconografia de los jóvenes fanáticos del fútbol organizados en las llamadas barras bravas. Postulamos que no se trata de un traspaso de contenidos ideológicos o políticos sino sobre todo de formas, símbolos y maneras de comportarse.

Si observamos los nombres que toman las distintas barras distritales de los principales equipos de fútbol del país, autopercibidos como los batallones locales de un ejército de hinchas, la experiencia de la violencia política es más que evidente. De un lado, en el caso de Alianza Lima, el ejército es "Comando Sur" y sus principales batallones son "Barraca Rebelde" (La Victoria y Barrios Altos), "Guerrilla” (Breña), "Artillería Sur" (San Juan de Lurigancho), "Rebeldes" (Comas), "Cabezas Azules" (San Martín de Porras), "Radicales" (Independencia), "Genocidas" (Breña), "Sicarios" (Villa E1 Salvador), "Malditos" (Surquillo), "Apocalipsis" (Rímac), "La Coalición" (Magdalena), y otros grupos como "Pueblo Grone" (Pueblo Libre), "La Calle" (Los Olivos) "Infierno" (Vitarte), "E1 Cartel" (San Borja), "Los Cardenales" (Santa Anita), etc. De otro lado, en el caso de Universitario, su ejército es "Trinchera Norte" y sus principales batallones distritales son "Holocausto" (Rímac), "La Turba" (Magdalena), "La Tropa" (San Juan de Lurigancho), "Artillería" (La Molina), "Falange" (San Martín de Porres), "Saigón" (Vitarte), "La Brigada" (Surco)," Agustinorte" (El Agustino), "La Causa" (San Borja)," Los Fugitivos" (Independencia) y "Chicago Chico" (Surquillo), etc.

Igual sucede con los cánticos, lemas y relatos verbales producidos por las barras de fútbol. Luis Fernando Chueca, analizando la producción verbal de "Comando Sur", encuentra cuatro relatos fundamentales: el relato de la guerra, el relato de la delincuencia, el relato de la catástrofe y el relato de la territorialidad. Chueca plantea, en la misma línea que este artículo, que estos relatos estructuran un espejo verbal de la sociedad (representación le llamamos nosotros), en donde están presentes los principales actores del enfrentamiento nacional. Evidentemente es una representación parcial y fragmentada de la sociedad, pero es aquélla que maneja un grupo de jóvenes y adolescentes, por lo general excluidos de los mecanismos de integración social, pero con un reclamo violento de protagonismo individual y grupal ${ }^{6}$.

Los criterios de status y jerarquía en estas barras también revelan el impacto de la violencia política de los años ochenta. En efecto, en las posiciones de mayor jerarquía ya no se encuentran los líderes antiguos, mayores de edad y clientes de los dirigentes de los clubes, sino nuevos líderes jóvenes
6. Chueca, Luis Fernando : "Las palabras de la tribu. Aproximaciones a la producción verbal de las barras bravas de Alianza Lima". Flecha en Azul N ${ }^{\circ}$ 6/7, Ceapaz, Lima: Ceapaz, 1998. 
que se han encumbrado a esta posición por su competencia en el enfrentamiento físico o "guerreo" contra los "enemigos", llámense otras barras o la policía. Ellos también destacan por su entrega incondicional, "hasta la muerte," con una determinada identidad futbolística y sus territorios y emblemas más importantes. A estos atributos de guerrero o peleador callejero se les suma la necesidad de mantener el rol de intermediación entre el club y la masa de barristas, con el objeto de asegurar algunos beneficios grupales como entradas gratis o subvencionadas a los partidos de fútbol, camisetas con los colores del club, banderas y apoyo económico para viajar a provincias a alentar al equipo de sus amores. Estos líderes son conocidos sólo por sus alias o sobrenombres, en una especie de clandestinidad que hay que mantener en todo momento, en especial con la policía y la prensa, bajo pena de castigo físico a quien se atreva a cometer una infidencia.

Luego, en una posición inferior, se encuentra un número determinado de "brigadieres" que son los que rodean al lider y tienen la responsabilidad de vigilar en las graderías que todos canten desaforadamente o "guerreen" en defensa de sus colores. Por lo general se paran de espaldas al campo de juego, usan algunos distintivos que los identifican o andan con el torso desnudo. Pobre aquel individuo que se ubique en la barra y no cante ni grite los 90 minutos que dura un partido. Para este infractor hay una serie de llamadas de atención que van desde los gritos o insultos hasta golpes arteros y la expulsión del territorio de la barra. Estos brigadieres son además quienes imponen los "cupos" a los distintos grupos barriales que se les acercan con el objeto de pertenecer a la barra principal.

Debajo de los brigadieres se encuentra la masa de jóvenes y adolescentes, los llamados "soldados", la tropa que debe mostrarse en todo momento beligerante, con gestos adustos, rostros pintados y movimientos de cuerpo que asemejan danzas tribales. Son ellos los dispuestos a gritar hasta quedar sin voz, a pelear en defensa de sus colores o mostrarse como los más fieros; así se sale del anonimato, se hacen méritos, y se puede ir ascendiendo en la jerarquía de la barra brava. El status que se logra y el respeto que se impone a los demás están fuertemente vinculados a muestras de agresividad y ejercicio de la violencia. La violencia no es sólo contra los "otros", el orden público u otras barras, sino también contra el propio entorno, al interior de la misma comunidad con amigos, parientes e incluso compañeros de la misma barra. La violencia interpersonal es un rasgo central en la vida cotidiana de estos jóvenes. 
Sin embargo no debemos exagerar. La violencia en el fútbol peruano tiene un fuerte sentido simbólico, teatral, de puesta en escena y representación pero no un alto costo social. En efecto, las muertes causadas directa o indirectamente en el fútbol entre 1994 y 1998, según una revisión exhaustiva de periódicos, han sido cerca de una veintena. Cantidad menor que las causadas por accidentes en las carreteras del país durante los dos últimos fines de semana. Los grupos de barristas son, en realidad, grupos de adolescentes y jóvenes nucleados territorialmente para profesar una misma lealtad futbolística e ir periódicamente al estadio, en peregrinaje, a reafirmarla. A diferencia de algunas barras argentinas, no constituyen fuerzas de choque al servicio de disputas locales. Lo importante para estos muchachos es saltar, gritar, lanzar piedras, asustar a sus mayores y parecer lo más malos posibles. Mejor aún frente a las cámaras de televisión que los hace salir del anonimato e invadir los hogares de millones de televidentes. Con este comportamiento buscan hacerse "hombres", es decir, construir una masculinidad agresiva y radical.

\section{LOS GUERREROS}

Pero la pregunta que queda por responder es ¿quiénes son estos muchachos que constituyen el núcleo duro o más militante de estas barras? ¿De dónde vienen y por qué se sienten atraídos por estas formas colectivas de organización y comportamiento? Recientes estudios etnográficos y otras evidencias empíricas a las que tenemos acceso muestran que el núcleo más militante de las barras está formado por niños y jóvenes entre 13 y 20 años, de sexo masculino, sin escuela ni empleo, y provenientes de familias pobres con fuertes necesidades materiales y graves conflictos internos. Son muchachos que desde niños salen o son empujados a la calle a "buscárselas" por sí mismos, es decir, a enfrentar una vida diaria llena de necesidades, obstáculos, incertidumbres y "enemigos" por doquier a los que desconocen. Estos jóvenes no tienen más recursos personales para la lucha por la sobrevivencia que la violencia interpersonal aprendida en la familia, la escuela, el barrio y las barras bravas ${ }^{7}$.

Esta pobreza de recursos sumada a que sus experiencias de vida son extremadamente locales, hacen que ellos perciban otros barrios o territorios como amenazas o enemigos potenciales. Al igual que los hooligans ingleses, sólo en compañia de sus pares o gente a quien conocen toda la vida es que estos jóvenes barristas se sienten seguros. Más aún
7. Thierold, Jorge (1998): "Informe sobre el imaginario de un grupo de barristas de Comando Sur". Asociación Civil ProNiño Íntimo-Unicef. Mimeo. 
8. Elias, Norbert y Eric Dunning . Deporte y ocio en el proceso de civilización. México DF: Fondo de Cultura Económica, 1986. cuando están en grupo guerreando con otras barras enemigas ellos sienten que su poder es mayor ${ }^{8}$.

La violencia de las barras parece iluminar cambios significativos en el funcionamiento de las familias de los barristas, donde parecen haber ocurrido rupturas generacionales más acentuadas que en familias de otros grupos sociales. Creemos que en estas familias la figura paterna no está presente o constituye un antimodelo, o tiene dificultades para transmitir ideas, valores $\mathrm{u}$ orientaciones a sus hijos menores. Estos últimos, a su vez, no tienen en su entorno inmediato figuras guías en quien apoyarse o cogerse con desesperación. Por esta razón estos muchachos se vuelcan en busca de sus pares e iguales en calles, esquinas, colegios, tribunas u otros lugares públicos. Allí, en estos espacios generacionales, recrean formas de familias espirituales o simbólicas como las pandillas de barrio o colegio, los clubes de fans o las barras bravas del fútbol.

En estas formas de organización social es donde se encuentra la solidaridad entre iguales, información para la vida, oportunidades de desahogo emocional y recreación, y un sentido de pertenencia a una identidad comunitaria irreductible. Al mismo tiempo, las barras son el lugar donde los jóvenes se enfrascan en procesos accidentados de construcción de status y reconocimiento tanto individual como colectivo. Lo particular es que la lucha por el reconocimiento se basa en un paradigma de masculinidad agresiva, cosificado en la figura del guerrero callejero. Éstos son adolescentes sin empleo ni futuro que se representan como guerreros o soldados, hermanados por lealtades futbolísticas, y que van de barrio en barrio exigiendo ser reconocidos como "hombres" mediante la agresión, el graffiti y los extremismos verbales.

La violencia real o simbólica es aquí la fuente de reputación, el respeto y la búsqueda de emociones fuertes. Hay, entonces, un sentido instrumental en el uso de la violencia y no es sólo mera conducta desbordada o producto del resentimiento como, por lo general, lo muestran los medios de comunicación. Como toda masculinidad que se afirma en el enfrentamiento, es una masculinidad homofóbica y antifemenina y, por tanto, poco democratizante. Es más, el peor insulto que puede recibir uno de estos guerreros callejeros está asociado a rasgos femeninos. Incluso las pocas mujeres que participan de las barras bravas en Perú construyen su prestigio como "machas" o "bronqueras" y no como mujeres.

En resumen, el fútbol no es sólo una actividad recreativa e intranscendente sino también una ventana para observar procesos más profundos que afectan la vida de los pue- 
blos. En nuestro caso, la experiencia de años de enfrentamiento y terrorismo y los cambios en las relaciones intergeneracionales en un sector de las familias más pobres, parecen darle el contenido violentista que lamentablemente acompaña a nuestro fútbol últimamente. 